\title{
Chemotherapy for Gastric Cancer - What Comes Next?
}

\author{
Shouji Shimoyama
}

Additional information is available at the end of the chapter

\section{Introduction}

Gastric cancer (GC) is the fourth (in men) and fifth (in women) most commonly newly diagnosed cancer worldwide and the third (in men) and fifth (in women) leading cause of cancer death [1]. Radical resection remains the only way cure, but cure rates following surgery for resectable GC in the West lag behind those in Japan. In addition, many GC patients will suffer recurrence even after curative resection in approximately $50 \%$ of cases [2], which eventually results in a still poor 5-year survival rate of $<30 \%$ both in the USA [3] and in Europe [4]. Although the 5-year survival rate in Japan is much better than that in the West, there is a global consensus that advanced GC patients need further anticancer therapy.

Currently, five classes of cytotoxic agents (fluoropyrimidines, platinums, taxanes, topoisomerase inhibitors, and anthracyclines) and new molecular targeting agents have been used in GC. Recent randomized controlled trials (RCTs) in the field of treatment for advanced GC have established first-line chemotherapy, although the approach and management for advanced GC varies from region to region so that there is no worldwide consensus on this matter. The most promising regimens are ECF (epirubicin, cisplatin, and 5-fluorouracil) in Europe [5], DCF (docetaxel, cisplatin, and 5-fluorouracil) in the USA (V325 trial) [6], and SP (S-1 and cisplatin) in Japan (SPIRITS trial) [7]. Strikingly, however, the global RCT conducted in the USA (FLAGS trial) failed to exhibit any survival advantage of the SP regimen over the FP (5-fluorouracil plus cisplatin) regimen [8]. Very recently, trastuzumab combined with cisplatin and fluoropyrimidines has been found to be active for human epidermal growth factor receptor-2 (HER2 or ERBB2)-positive GC (ToGA trial) [9]. Although these regimens are active, the treatment progress is painfully slow [4]. The median time to progression (TTP) or progression free survival (PFS) was 7.4 months by ECF [5], 5.6 months by DCF [6], 6.0 months by Japanese style SP [7], 4.8 months by global style SP [8], and 6.7 months even by adding trastuzumab [9], suggesting that many advanced GC patients experience failure after first-line chemotherapy. 
Interestingly, the median TTP or PFS of these regimens are almost equivalent (5.6-7.4 months) [5-7] while median overall survival times (OS) differ between the studies (Figure 1). The 13 months of median OS by the Japanese SP regimen [7] was apparently longer than those (8.7-9.2 months) by ECF and DCF regimens [5,6] (Figure 1). In addition, even by the use of the SP regimen, the post-progression survival -the survival length difference between median PFS and median OS- differed considerably, being 7 months in the SPIRITS trial [7] and 3.8 months in the FLAGS trial [8] (Figure 1). Such inter-trial differences in post-progression survival are partly attributable to different proportions of subsequent second-line therapy after the failure of first-line chemotherapy, being over $70 \%$ in the SPIRITS trial while $30-45 \%$ in other trials [6, $8,9]$. In this regard, patients who retain good performance status at the time of first-line treatment failure are candidates for second-line therapy. Currently, however, no standard regimens for any second-line therapy hitherto determined suggest an urgent need for the establishment of second-line therapy. Reflecting this urgency, clinical research concerning second-line therapy has been recently commenced. In the era of post first-line chemotherapy, this chapter reviews the next research issues deserving of focus in the field of advanced GC treatment.

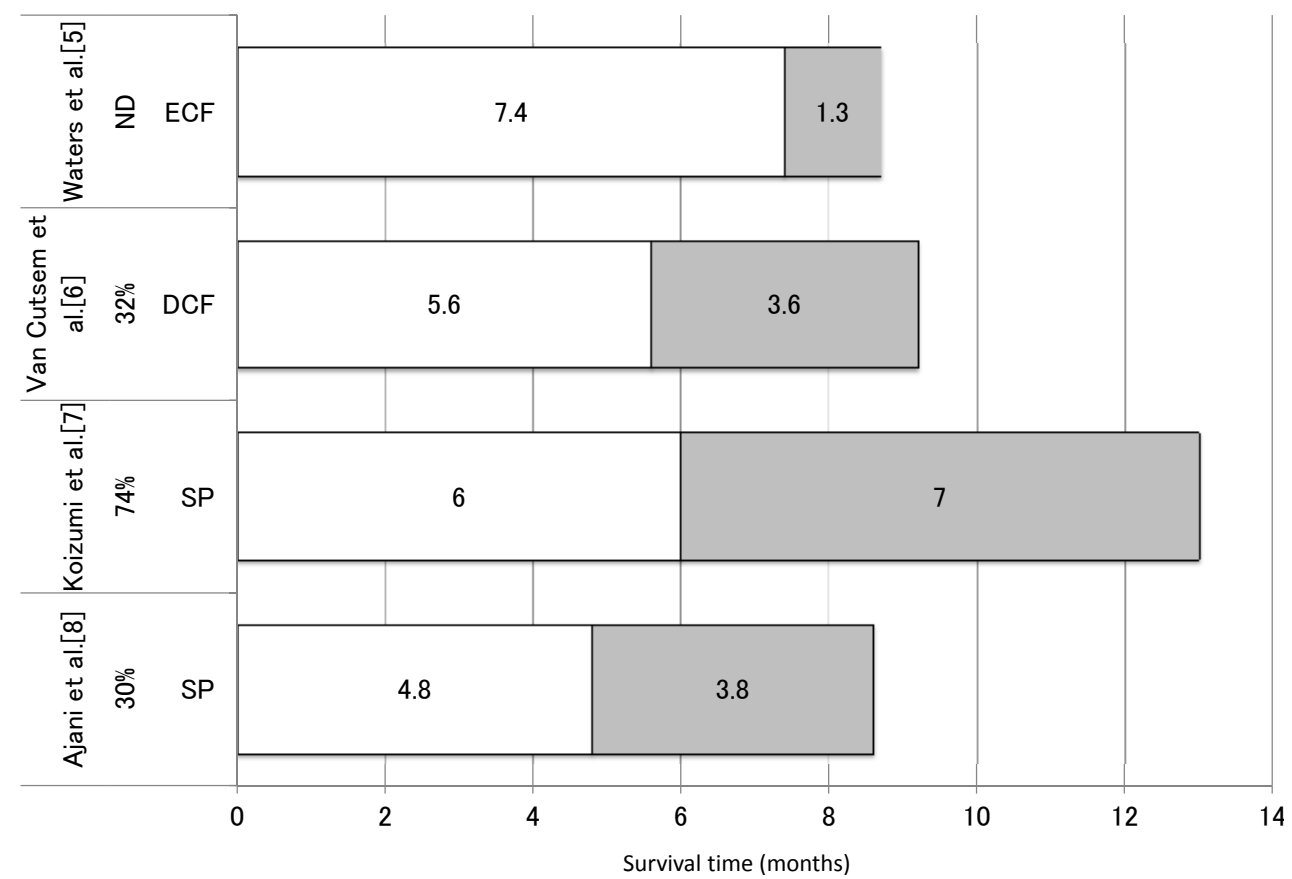

Figure 1. Median TTP or PFS (white bar) and post-progression free survivals (gray bar) of the previous first-line RCTs. The sum of the white and gray bars indicates median OS. Percentages indicate the proportion of patients receiving further therapy. The reference numbers are expressed in brackets. ECF; epirubicin, cisplatin, and 5-fluorouracil, DCF; docetaxel, cisplatin, and 5-fluorouracil, SP; S-1 and cisplatin. ND; not described. 


\section{Rationale for second-line therapy}

The significance of second-line therapy after disease progression by first-line chemotherapy has been evaluated by several randomized comparisons of survival times between second-line therapy and best supportive care (BSC) or placebos. Various kinds of agents have been investigated in the RCTs of second-line therapy, such as chemotherapy drugs [10-12] and molecular targeting agents [13-15]. Some of these trials have demonstrated significantly improved survival times by second-line therapies as compared with BSC or a placebo (Table 1).

The AIO conducted a RCT to compare irinotecan (21 patients) with BSC (19 patients) [10]. Although this study was closed prematurely due to poor patient accrual, irinotecan could significantly ( $\mathrm{p}=0.012)$ prolong median OS (4.0 months) as compared to those by BSC (2.4 months). The second RCT conducted in Korea [11] assigned patients in a ratio of 2:1 to chemotherapy (docetaxel or irinotecan) plus BSC (133 patients) or BSC alone (69 patients). Choice of chemotherapy drugs was left to the discretion of the investigators. Median OS of the chemotherapy arm (5.3 months) was significantly $(\mathrm{p}=0.007)$ longer than those of the BSC arm (3.8 months). This survival difference may be partly ascribed to the significantly $(p=0.02)$ greater number of patients receiving further chemotherapy (third-line chemotherapy) in the chemotherapy arm $(40 \%)$ than in the BSC arm (22\%) because median OS was longer (8.0 months) for patients who received subsequent treatment than those who did not ( 3.76 months), regardless of treatment arm. Of note, the lack of any difference in median OS between docetaxel use (5.2 months) and irinotecan use (6.5 months) implies that both agents are equally active, although bias for patient allocation can not be denied. In the third RCT conducted in the UK [12], 168 patients were allocated to either docetaxel plus active symptom control or active symptom control alone (84 patients each). The median OS in the docetaxel group (5.2 months) was significantly longer $(p=0.01)$ than that in the active symptom control alone group (3.6 months). Measurements of disease specific quality of life showed benefits for docetaxel in reducing dysphagia and abdominal pain.

The efficacy of molecular targeting agents as a second-line setting has been investigated by three other RCTs [13-15]. First, a GRANITE-1 trial [13] randomly assigned 656 patients at a 2:1 schedule either to everolimus $(n=439)$ or a matching placebo $(n=217)$. Significantly longer median PFS by everolimus (1.7 months, $\mathrm{p}<0.0001)$ than that by placebo (1.4 months) did not reflect a difference in median OS (5.4 months in the everolimus arm versus 4.3 months in the placebo arm, $\mathrm{p}=0.12)$. Such a discrepancy, namely a significant PFS difference and nonsignificant OS difference, could be ascribed to the fact of the similar or even longer median OS (4.3 months) in the placebo arm in this study as compared to those (2.4-3.8 months) of BSC arms in other second-line RCTs [10-12]. Therefore, one should remember that the longer survival length in the control arm might diminish any statistical significance even when the experimental regimen is effective. Subsequently, a global REGARD trial [14] was able for the first time to demonstrate that ramucirumab, a monoclonal antibody of vascular endothelial growth factor receptor (VEGFR)-2, was significantly superior to placebo with regard to median OS (5.2 months versus 3.8 months, $\mathrm{p}=0.047)$ and median PFS ( 2.1 months versus 1.3 months, $\mathrm{p}<0.0001)$, respectively. In addition, more patients receiving ramucirumab experienced stable or im- 
proved QOL than those in the placebo arm. Finally, apatinib, a tyrosine-inhibitor agent targeting VEGFR with an anticipated anti-angiogenesis effect, has been now tested in a clinical trial (NCT 01512745) [15]. This study aims to determine whether apatinib can improve PFS or OS compared to placebos.

Subsequently, a metaanalysis has very recently elucidated a $36 \%$ reduction in the risk of death $(p<0.0001)$ by second-line therapy [16], suggesting that second-line therapy is effective and should be considered in some segments of GC patients refractory to first-line therapy.

\section{Seeking the best regimen of second-line therapy}

Several randomized trials have been released to explore the optimal combination and doses for second-line therapy using the currently active agents or those deemed active. The agents investigated by these trials include chemotherapeutic drugs [17-20], a molecular targeting agent [21], and their combinations [22-26].

The efficacy of chemotherapy as a second-line setting has been investigated in several RCTs. In the TCOG GI-0801 trial [17], median PFS was significantly longer (3.8 months, $n=64$ ) by biweekly irinotecan plus cisplatin than by irinotecan alone ( 2.8 months, $n=63)$, but median OS did not differ between the arms (10.7 months versus 10.1 months). Notably, the proportion of patients receiving third-line therapy was the same (75\%) in both groups. The results of another randomized trial (ECRIN) have been reported in the abstract form [18], in which irinotecan plus cisplatin $(n=84)$ was compared with irinotecan alone $(n=84)$ in patients refractory to an S-1 containing regimen. WJOG 4007 [19] is a RCT comparing weekly paclitaxel $(n=108)$ with biweekly irinotecan $(n=111)$ in GC patients refractory to fluoropyrimidines plus cisplatin. Although there are no statistically significant differences between weekly paclitaxel and biweekly irinotecan for median OS (9.5 months vs 8.4 months, $\mathrm{p}=0.38$ ), median PFS (3.6 months vs 2.3 months, $\mathrm{p}=0.33)$, or response rate $(20.9 \%$ vs $13.6 \%, \mathrm{p}=0.24)$, the median OS of both arms are equally longer than those of the previous second-line studies (Table 1, Figure 2). Several explanations are possible for the longer median OS in this study. One explanation is the lower proportion of patients with severe peritoneal metastasis in this study $(25.6 \%)$ as compared with those in the AIO [10] (45\%) and Kang [11] (45\%) studies. Another explanation is that the proportion of patients receiving third-line therapy in this study was substantial, being $89.8 \%$ in the paclitaxel arm and $72.1 \%$ in the irinotecan arm. Interestingly, the third-line therapy was an irinotecan-containing regimen in $75 \%$ of patients of the paclitaxel arm and a taxanecontaining regimen in $60 \%$ of the irinotecan arm. Including later lines, $81 \%$ patients in the paclitaxel arm received irinotecan and $68 \%$ of patients in the irinotecan arm received paclitaxel. The more prolonged median OS in both arms of the WJOG 4007 than those of the previous studies implies that both irinotecan and paclitaxel in second- and further-line settings could potentially contribute to prolonged survival. The ongoing fourth RCT (JACCRO GC05) [20] has been comparing irinotecan plus S-1 with irinotecan alone to GC patients refractory to S-1. Since the standard regimen in adjuvant and advanced settings in Japan is respectively S- 1 and S-1 plus cisplatin, this study will provide one answer to the clinically important question of whether the prolonged use of S-1 is effective even to the S-1 resistant patients whom the clinicians face. 


\begin{tabular}{|c|c|c|c|c|c|c|c|c|}
\hline & \multirow[b]{2}{*}{ Study drug } & \multirow[b]{2}{*}{ Dose and schedule } & \multicolumn{4}{|c|}{ Number of patients median OS } & \multicolumn{2}{|c|}{ median PFS } \\
\hline & & & $\begin{array}{l}\text { Study } \\
\text { arm }\end{array}$ & $\begin{array}{l}\text { Control } \\
\text { arm }\end{array}$ & $\begin{array}{l}\text { Study } \\
\text { arm }\end{array}$ & $\begin{array}{l}\text { Control } \\
\text { arm }\end{array}$ & $\begin{array}{l}\text { Study } \\
\text { arm }\end{array}$ & $\begin{array}{l}\text { Control } \\
\text { arm }\end{array}$ \\
\hline Thuss-Patience [10] & Iriontecan & $250-350 \mathrm{mg} / \mathrm{m} 2, \mathrm{q} 3 \mathrm{w}$ & 21 & 19 & $\begin{array}{l}4 \\
p=0.012\end{array}$ & 2.4 & 2.5 & ND \\
\hline Kang [11] & $\begin{array}{l}\text { Iriontecan or } \\
\text { Docetaxel }\end{array}$ & $\begin{array}{l}150 \mathrm{mg} / \mathrm{m} 2, \mathrm{q} 2 \mathrm{w} \text { or } \\
60 \mathrm{mg} / \mathrm{m} 2, \mathrm{q} 3 \mathrm{w}\end{array}$ & 133 & 69 & $\begin{array}{l}5.3 \\
p=0.007\end{array}$ & 3.8 & ND & ND \\
\hline COUGAR-02 [12] & Docetaxel & $75 \mathrm{mg} / \mathrm{m} 2, \mathrm{q} 3 \mathrm{w}$ & 84 & 84 & $\begin{array}{l}5.2 \\
p=0.01\end{array}$ & 3.6 & ND & ND \\
\hline GRANITE-1 [13] & Evelorimus & $10 \mathrm{mg} /$ day & 439 & 217 & $\begin{array}{l}5.4 \\
p=0.12\end{array}$ & 4.3 & $\begin{array}{l}1.7 \\
p<0.001\end{array}$ & 1.4 \\
\hline REGARD [14] & Ramucirumab & $8 \mathrm{mg} / \mathrm{kg}, \mathrm{q} 2 \mathrm{w}$ & 238 & 117 & $\begin{array}{l}5.2 \\
p=0.047\end{array}$ & 3.8 & $\begin{array}{l}2.1 \\
p<0.0001\end{array}$ & 1.3 \\
\hline
\end{tabular}

OS; overall survival, PFS; progression free survival, ND; not described

Table 1. Published results of randomized controlled trials of second-line therapy versus best supportive care or placebo.

The RCT comparing a molecular targeting agent with a chemotherapeutic agent has been ongoing. HER2-positive advanced GC patients have been allocated to either trastuzumab emtansine or taxane (GATSBY, NCT01641939) [21].

A combination of molecular targeting agents and chemotherapy agents has been investigated in several RCTs. First, paclitaxel with or without lapatinib, which binds to the intracellular tyrosine kinase domains of ERBB1 and ERBB2 (HER2), was compared in HER2-positive advanced GC (TYTAN) [22]. Neither median OS nor median PFS were prolonged by lapatinib plus paclitaxel $(n=132)$ as compared to paclitaxel alone $(n=129)$. Second, the results of the RAINBOW trial $[23,24]$, which compared ramucirumab plus paclitaxel with placebo plus paclitaxel, have been very recently reported in the abstract form. Sixty hundred and sixty-five GC patients, who were refractory to cisplatin and fluoropyrimidine-containing regimens, were randomized in a 1:1 ratio to receive paclitaxel plus ramucirumab or paclitaxel plus a placebo. The paclitaxel and ramucirumab arm showed a significant benefit in median OS (HR=0.807, $\mathrm{p}=0.0169)$ and median PFS ( $\mathrm{HR}=0.635, \mathrm{p}<0.0001)$. The subsequent geographical regionstratified analysis elucidated that the advantage of median PFS and median OS was more evident in Western patients than in Japanese patients (Figure 2). Such a regional difference could partly explained by a higher use of post-discontinuation treatment in Japan $(75 \%$ of patients) than in Western countries (36-38\% of patients), which may eventually mask any potential OS benefit of ramucirumab plus paclitaxel in Japan. Two other RCT trials $[25,26]$ are now ongoing. Paclitaxel with or without everolimus has been compared in patients with advanced GC refractory to fluoropyrimidine containing regimens [25]. Patients will be randomized in a 1:1 ratio for a total of 240 patients per treatment arm. Nimotuzumab plus irinotecan versus irinotecan monotherapy as second-line therapy has been investigated in 


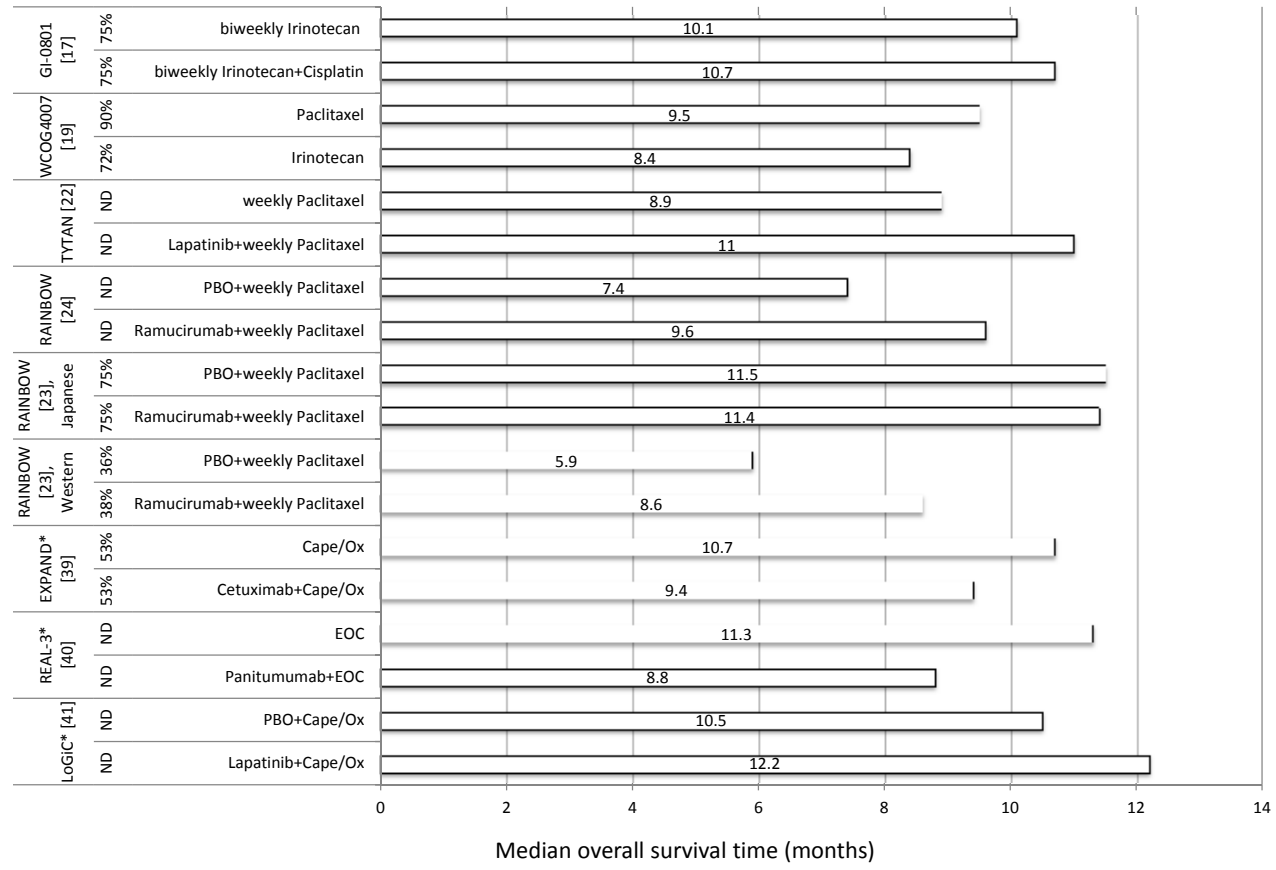

Figure 2. Comparisons of median OS between the previous RCTs. The percentage indicates the proportion of patients receiving further therapy in each trial. The reference numbers are expressed in brackets. *; first-line trials, BSC; best supportive care, PBO; placebo, Cape; capecitabine, Ox; oxaliplatin, EOC; epirubicin, oxaliplatin, and capecitabine, ND; not described.

patients with ERBB1 overexpressed advanced GC [26]. This is a Japan and Korea collaborative RCT allocating patients at 1:1 ratio for a total of approximately 400 patients per arm.

The results of some trials have been published; however, at present, trials in which the primary endpoint has been met have been unfortunately very limited. The positive results hitherto obtained include a prolonged PFS by a combination of irinotecan and cisplatin after the failure of S-1 based first-line chemotherapy, and prolonged PFS and OS by ramucirumab in combination with weekly paclitaxel. The results of other studies, especially using molecular targeting agents, are awaited.

\section{Consideration of adverse events}

When considering second-line therapy, clinicians must be aware that, by definition, patients receiving second-line therapy are not chemonaive and experience treatment failure; thus, they are more likely to be resistant to therapy than first-line treatment. Furthermore, patient performance status is more likely to deteriorate due to a recurrent cancer burden and treatment 
against it. Indeed, widely ranging grades of gastrointestinal symptoms-related adverse events occurred in a substantial proportion of patients in the BSC arms of clinical trials, suggesting a poor quality of life even by the BSC. In addition, a more intensive regimen aiming at a prolonged OS may cause a higher likelihood of severe adverse events that may result in treatment discontinuation and limitation. For example, the DCF regimen caused $82 \%$ of grade 3-4 neutropenia and $29 \%$ of febrile neutropenia. Therefore, balancing efficacy and adverse events should be taken into account when developing second-line therapy. The development of more intensive while less toxic second-line regimens could be positioned as a breakthrough marker of GC treatment, which can then ultimately achieve further survival prolongation without treatment withdrawal.

In this context, another direction for research is to establish less toxic regimens with preserved anticancer activity. As described earlier, the conventional first-line treatment comprises 5fluorouracil and emetogenic/nephrotoxic cisplatin. Therefore, the challenges for a less toxic regimen are the substitution of oxaliplatin for nephrotoxic cisplatin $[27,28]$ or substitution of oral capecitabine for intravenous 5-fluorouracil [29]. Such substitutions aim to reduce toxicity and maintain organ function, thus avoiding treatment withdrawal and prolonged treatment duration.

Fluorouracil, leucovorin, and oxaliplatin (FLO) were associated with significantly less anemia, nausea, vomiting, fatigue, renal toxicity, and serious adverse events related to the treatment as compared with fluorouracil, leucovorin, and cisplatin (FLP) [27]. In addition, there was a better trend toward improved median PFS by FLO than FLP. Similarly, as compared to SP, S-1 plus oxaliplatin (SOX) resulted in a reduced risk of grade $3 / 4$ neutropenia (41.5\% vs $19.5 \%$ ) and febrile neutropenia $(6.9 \%$ vs $0.9 \%)$ while median PFS was similar between the two regimens (5.4 months versus 5.5 months) [28]. These findings further support the possibility that the substitution of oxaliplatin for cisplatin reduced toxicity while maintaining efficacy. Accordingly, length of hospital stay per cycle of SOX regimen (0.85 day) was significantly shorter than that for the SP regimen (6 days) [28]. Furthermore, capecitabine and cisplatin (XP) versus 5-fluorouracil and cisplatin (FP) proved similar median OS (10.5 months versus 9.3 months), suggesting that the inconvenience of infusional 5-fluorouracil could be replaced by oral capecitabine, thus realizing a more simplified dosing schedule [29]. Whether this concept can be applied to second-line therapy warrants further investigation.

\section{Future perspectives}

With the development of a new generation of cytotoxic agents and molecular targeting agents, the research field of GC treatment appears to be transitioning into a new era with a focus on the targetable molecules in GC. Several molecular targeting agents are currently being evaluated both in first- and second-line settings. The pending results of ongoing clinical trials motivates researchers to continue the challenge of establishing the best second-line regimens or less toxic combinations for the treatment of advanced GC. 
a. Clarifying the genetic alterations of targeted molecules and their interactions.

Unfortunately, in sharp contrast to colorectal cancer in which there has been a significant achievement in treatment by the use of molecular targeting agents, only one agent (ramucirumab) has been currently proved to be an agent for second-line therapy presumably due to the genetic complexity and molecular heterogeneity of the disease.

Recent findings have highlighted the mechanisms of the actions of molecular targeting agents or patterns of expression of targetable molecules in several tumors. For example, genetic alterations that are critical for cell growth occur with considerably different frequencies, being $60 \%, 33 \%$, and $32 \%$ in cancers of the pancreas, biliary tract, and colon, respectively [30]. Furthermore, certain combinations of targets are expressed in a mutually exclusive or cooccurring manner in the same tumor. A mutually exclusive fashion would be a case being KRAS and BRAF in colorectal cancer, or ERBB1 and KRAS in lung cancer [31]. The co-occurring expression of targets is a case of being ERBB2 and PIK3CA in breast cancer [32]. With regard to GC, although KRAS mutations are initially recognized as an infrequent phenomenon in GC [33], the alterations and amplifications of other genes --both known or previously unreported-have been subsequently found in a substantial number of GC patients in a mutually exclusive manner [34,35] or co-amplified manner [36]. These findings create a challenge in the treatment regimen with either a use of each blockade of each targetable molecule or a use of dual- or paninhibitors of kinases [37]. In addition, elucidation of the roles of each domain in ERBB2 that plays a role in resistance to anti-HER2 therapy further provides the theoretical basis to modify therapeutic strategies to circumvent this resistance [38]. These advances may expand therapeutic options, thereby making larger proportions of GC patients possible candidates for molecular targeting therapies than previously appreciated. Accordingly, there may be a desperate need for multiple gene profiling which could help establish rational molecular criteria for patient inclusion and exclusion in clinical trials. Patient selection by gene profiling may allow better patient recruitment for those most likely to respond to targeted therapies.

b. Positive and negative interactions between chemotherapy and molecular targeting therapies.

It should be noted that the recent clinical trials of first-line molecular targeting therapies regrettably resulted in some negative results [39-41] (Figure 2). The addition of cetuximab to cisplatin plus capecitabine had a similar median PFS (4.4 months) and median OS (9.4 months) compared to cisplatin plus capecitabine alone (5.6 months and 10.7 months, respectively) [39] (EXPAND). Surprisingly, the addition of panitumumab to epirubicin, oxaliplatin, and capecitabine $(E O C)$ resulted in a significantly shorter $(\mathrm{p}=0.013)$ median OS (8.8 months) compared to EOC (11.3 months) (REAL-3) [40]. Furthermore, lapatinib in combination with capecitabine and oxaliplatin could not show any significant survival benefit (LoGiC) [41]. These negative results lead to speculation that there may be ideal combinations or compatibility between chemotherapy and molecular targeting therapy. In addition, even the addition of panitumumab to EOC achieved only similar median OS to those of the WCOG 4007 trial (Figure 2) $[19,40]$. Therefore, a certain combination, such as anti-EGFR antibody and capeci- 
tabine or oxaliplatin, may be ineffective or even interfere with the other. This speculation can be supported by the observation that addition of cetuximab to oxaliplatin plus fluoropyrimidine-based chemotherapy failed to demonstrate survival benefits for advanced colorectal cancer [42].

c. Need to evaluate the updated molecular profile.

Another obstacle for the progression of second-line treatment lies in the possibility that the molecular profile of GC is likely to change under the stress of treatment. Generally, lower response rates and shorter survival times in patients receiving second-line therapy than chemonaive patients may partly be explained by such molecular changes that lead to a resistance to therapy. Ideally, the on-demand tissue samples from tumor sites currently of interest are needed to assess the updated genetic and molecular patterns and to predict whether the planned second-line therapy is really effective. However, direct tumor tissue sampling and subsequent gene analysis are often hampered by virtually inaccesible tumor localization and by overly small sample volumes to perform gene analysis. It is necessary to discover novel markers which can be alternatives for those obtained only by direct tumor tissue sampling as well as to improvise new methods to assess them in order to select the right patients for the right second-line regimen.

Motivated by the first promising results of trastuzumab use in the ToGA trial, several molecular targeting therapies have been challenged in clinical trials. Continuous efforts should be necessary to clarify the mutation and amplification of targeted molecules, and novel methods for their genetic profiling should probably become part of clinical routines. Ultimately, GC patients harboring unique genetic profiles of targeted molecules should be allocated into specific, suitable trials. Targeted therapies tailored to individual genetic profiles maximize treatment efficacy because this allows the recruitment of selected, most suitable patients rather than unselected ones [43].

\section{Conclusions}

Against the background of survival advantages of second-line therapy over BSC in GC patients refractory to first-line treatment, efforts to establish the most effective regimens have been just begun. Parallel to the development of molecular targeting agents, the investigated regimens comprise doublet or triplet chemotherapeutic agents, molecular targeting agents, and their combinations. In addition, the minimization of adverse events should be taken into account to avoid treatment discontinuation. There is a desperate need to explore genetic mutations of targeted molecules and the interactions between them, to establish novel methods to assess them, to clarify the positive or negative interactions between chemotherapy and molecular targeting agents, and to find regimens in which adverse events are least likely to occur for avoiding treatment discontinuation. These could help determine rational molecular criteria for patient inclusion and exclusion in clinical trials, realize the most efficient patient recruitment for those most likely to respond to therapies, and accelerate the establishment of the most effective second-line therapy that could achieve greater survival prolongation. 


\section{Author details}

Shouji Shimoyama

Address all correspondence to: shimoyama@apost.plala.or.jp

Gastrointestinal Unit, Settlement Clinic, Towa, Adachi-ku, Tokyo, Japan

\section{References}

[1] Jemal A, Bray F, Center MM, Ferlay J, Ward E, Forman D. Global cancer statistics. CA Cancer J Clin. 2011; 61(2): 69-90.

[2] Buzzoni R, Bajetta E, Di Bartolomeo M, Miceli R, Beretta E, Ferrario E, Mariani L. Pathological features as predictors of recurrence after radical resection of gastric cancer. Br J Surg. 2006; 93(2): 205-9.

[3] Siegel R, Ma J, Zou Z, Jemal A. Cancer statistics, 2014. CA Cancer J Clin. 2014; 64(1): 9-29. doi: 10.3322/caac.21208.

[4] De Angelis R, Sant M, Coleman MP, Francisci S, Baili P, Pierannunzio D, Trama A, Visser O, Brenner H, Ardanaz E, Bielska-Lasota M, Engholm G, Nennecke A, Siesling S, Berrino F, Capocaccia R; EUROCARE-5 Working Group. Cancer survival in Europe 1999-2007 by country and age: results of EUROCARE--5-a population-based study. Lancet Oncol. 2014; 15(1): 23-34. doi: 10.1016/S1470-2045(13)70546-1.

[5] Waters JS, Norman A, Cunningham D, Scarffe JH, Webb A, Harper P, Joffe JK, Mackean M, Mansi J, Leahy M, Hill A, Oates J, Rao S, Nicolson M, Hickish T. Long-term survival after epirubicin, cisplatin and fluorouracil for gastric cancer: results of a randomized trial. Br J Cancer. 1999; 80: 269-72.

[6] Van Cutsem E, Moiseyenko VM, Tjulandin S, Majlis A, Constenla M, Boni C, Rodrigues A, Fodor M, Chao Y, Voznyi E, Risse ML, Ajani JA; V325 Study Group. Phase III study of docetaxel and cisplatin plus fluorouracil compared with cisplatin and fluorouracil as first-line therapy for advanced gastric cancer: a report of the V325 Study Group. J Clin Oncol. 2006; 24: 4991-7.

[7] Koizumi W, Narahara H, Hara T, Takagane A, Akiya T, Takagi M, Miyashita K, Nishizaki T, Kobayashi O, Takiyama W, Toh Y, Nagaie T, Takagi S, Yamamura Y, Yanaoka K, Orita H, Takeuchi M. S-1 plus cisplatin versus S-1 alone for first-line treatment of advanced gastric cancer (SPIRITS trial): a phase III trial. Lancet Oncol. 2008; 9(3): 215-21. doi: 10.1016/S1470-2045(08)70035-4.

[8] Ajani JA, Rodriguez W, Bodoky G, Moiseyenko V, Lichinitser M, Gorbunova V, Vynnychenko I, Garin A, Lang I, Falcon S. Multicenter phase III comparison of cisplatin/S-1 with cisplatin/infusional fluorouracil in advanced gastric or gastroeso- 
phageal adenocarcinoma study: the FLAGS trial. J Clin Oncol. 2010; 28(9): 1547-53. doi: 10.1200/JCO.2009.25.4706.

[9] Bang YJ, Van Cutsem E, Feyereislova A, Chung HC, Shen L, Sawaki A, Lordick F, Ohtsu A, Omuro Y, Satoh T, Aprile G, Kulikov E, Hill J, Lehle M, Rüschoff J, Kang YK; ToGA Trial Investigators. Trastuzumab in combination with chemotherapy versus chemotherapy alone for treatment of HER2-positive advanced gastric or gastrooesophageal junction cancer (ToGA): a phase 3, open-label, randomised controlled trial. Lancet. 2010; 376(9742): 687-97. doi: 10.1016/S0140-6736(10)61121-X.

[10] Thuss-Patience PC, Kretzschmar A, Bichev D, Deist T, Hinke A, Breithaupt K, Dogan Y, Gebauer B, Schumacher G, Reichardt P. Survival advantage for irinotecan versus best supportive care as second-line chemotherapy in gastric cancer--a randomised phase III study of the Arbeitsgemeinschaft Internistische Onkologie (AIO). Eur J Cancer. 2011; 47(15): 2306-14. doi: 10.1016/j.ejca.2011.06.002.

[11] Kang JH, Lee SI, Lim do H, Park KW, Oh SY, Kwon HC, Hwang IG, Lee SC, Nam E, Shin DB, Lee J, Park JO, Park YS, Lim HY, Kang WK, Park SH. Salvage chemotherapy for pretreated gastric cancer: a randomized phase III trial comparing chemotherapy plus best supportive care with best supportive care alone. J Clin Oncol. 2012; 30(13): 1513-8. doi: 10.1200/JCO.2011.39.4585.

[12] Ford HE, Marshall A, Bridgewater JA, Janowitz T, Coxon FY, Wadsley J, Mansoor W, Fyfe D, Madhusudan S, Middleton GW, Swinson D, Falk S, Chau I, Cunningham D, Kareclas P, Cook N, Blazeby JM, Dunn JA; COUGAR-02 Investigators. Docetaxel versus active symptom control for refractory oesophagogastric adenocarcinoma (COUGAR-02): an open-label, phase 3 randomised controlled trial. Lancet Oncol. 2014; 15(1): 78-86. doi: 10.1016/S1470-2045(13)70549-7.

[13] Ohtsu A, Ajani JA, Bai YX, Bang YJ, Chung HC, Pan HM, Sahmoud T, Shen L, Yeh KH, Chin K, Muro K, Kim YH, Ferry D, Tebbutt NC, Al-Batran SE, Smith H, Costantini C, Rizvi S, Lebwohl D, Van Cutsem E. Everolimus for previously treated advanced gastric cancer: results of the randomized, double-blind, phase III GRANITE-1 study. J Clin Oncol. 2013; 31(31): 3935-43. doi: 10.1200/JCO.2012.48.3552.

[14] Fuchs CS, Tomasek J, Yong CJ, Dumitru F, Passalacqua R, Goswami C, Safran H, dos Santos LV, Aprile G, Ferry DR, Melichar B, Tehfe M, Topuzov E, Zalcberg JR, Chau I, Campbell W, Sivanandan C, Pikiel J, Koshiji M, Hsu Y, Liepa AM, Gao L, Schwartz JD, Tabernero J; REGARD Trial Investigators. Ramucirumab monotherapy for previously treated advanced gastric or gastro-oesophageal junction adenocarcinoma (REGARD): an international, randomised, multicentre, placebo-controlled, phase 3 trial. Lancet. 2014; 383(9911): 31-9. doi: 10.1016/S0140-6736(13)61719-5.

[15] http://www.ClinicalTrial.gov. NCT 01512745

[16] Kim HS, Kim HJ, Kim SY, Kim TY, Lee KW, Baek SK, Kim TY, Ryu MH, Nam BH, Zang DY. Second-line chemotherapy versus supportive cancer treatment in ad- 
vanced gastric cancer: a meta-analysis. Ann Oncol. 2013; 24(11): 2850-4. doi: 10.1093/ annonc/mdt351.

[17] Higuchi K, Tanabe S, Shimada K, Hosaka H, Sasaki E, Nakayama N, Takeda Y, Moriwaki T, Amagai K, Sekikawa T, Sakuyama T, Kanda T, Sasaki T, Azuma M, Takahashi F, Takeuchi M, Koizumi W; Tokyo Cooperative Oncology Group, Tokyo, Japan. Biweekly irinotecan plus cisplatin versus irinotecan alone as second-line treatment for advanced gastric cancer: a randomised phase III trial (TCOG GI-0801/BIRIP trial). Eur J Cancer. 2014; 50(8): 1437-45. doi: 10.1016/j.ejca.2014.01.020.

[18] Inagaki H, Nishikawa K, Fujitani K, Sugimoto N, Shigematsu T, Ishiguro T, Tsuburaya A, Nakamura M, Nashimoto A, Yamane T, Yamada M, Imano M, Iijima S, Oka Y, Kataoka M, Hironaka S, Andoh H, Morita S, Sakamoto J, Tsujinaka T. Efficacy analyses of a randomized phase III clinical trial of combined therapy with CPT-11/CDDP versus CPT-11 alone in patients with advanced or recurrent gastric cancer refractory to prior S-1 chemotherapy. Proc ASCO 2013; abstr 69.

[19] Hironaka S, Ueda S, Yasui H, Nishina T, Tsuda M, Tsumura T, Sugimoto N, Shimodaira H, Tokunaga S, Moriwaki T, Esaki T, Nagase M, Fujitani K, Yamaguchi K, Ura T, Hamamoto Y, Morita S, Okamoto I, Boku N, Hyodo I. Randomized, open-label, phase III study comparing irinotecan with paclitaxel in patients with advanced gastric cancer without severe peritoneal metastasis after failure of prior combination chemotherapy using fluoropyrimidine plus platinum: WJOG 4007 trial. J Clin Oncol. 2013; 31(35): 4438-44. doi: 10.1200/JCO.2012.48.5805.

[20] http://www.ClinicalTrial.gov. NCT 00639327

[21] http://www.ClinicalTrial.gov. NCT 01641939

[22] Satoh T, Xu RH, Chung HC, Sun GP, Doi T, Xu JM, Tsuji A, Omuro Y, Li J, Wang JW, Miwa H, Qin SK, Chung IJ, Yeh KH, Feng JF, Mukaiyama A, Kobayashi M, Ohtsu A, Bang YJ. Lapatinib plus paclitaxel versus paclitaxel alone in the second-line treatment of HER2-amplified advanced gastric cancer in Asian populations: TyTAN--a randomized, phase III study. J Clin Oncol. 2014; 32(19): 2039-49. doi: 10.1200/JCO. 2013.53.6136.

[23] Hironaka S, Shimada Y, Sugimoto N, Komatsu Y, Nishina T, Yamaguchi K, Segawa Y, Omuro Y, Tamura T, Doi T, Yukisawa S, Yasui H, Nagashima F, Gotoh M, Esaki T, Emig M, Chandrawansa K, Muro K, Wilke H, Ohtsu A. RAINBOW: A global, phase III, randomized, double-blind study of ramucirumab (RAM) plus paclitaxel (PTX) versus placebo (PL) plus PTX in the treatment of metastatic gastroesophageal junction and gastric adenocarcinoma (mGC) following disease progression on first-line platinum- and fluoropyrimidine-containing combination therapy-Efficacy analysis in Japanese and Western patients. Proc ASCO 2014; abstr 4005

[24] Wilke H, Van Cutsem E, Oh SC, Bodoky G, Shimada Y, Hironaka S, Sugimoto N, Lipatov ON, Kim T-Y, Cunningham D, Ohtsu A, Rougier P, Emig M, Carlesi R, Chandrawansa K, Muro K. RAINBOW: A global, phase III, randomized, double-blind 
study of ramucirumab plus paclitaxel versus placebo plus paclitaxel in the treatment of metastatic gastroesophageal junction (GEJ) and gastric adenocarcinoma following disease progression on first-line platinum- and fluoropyrimidine-containing combination therapy rainbow IMCL CP12-0922 (I4T-IE-JVBE). Proc ASCO 2014; abstr LBA7

[25] http://www.ClinicalTrial.gov. NCT 01248403

[26] http://www.ClinicalTrial.gov. NCT 01813253

[27] Al-Batran SE, Hartmann JT, Probst S, Schmalenberg H, Hollerbach S, Hofheinz R, Rethwisch V, Seipelt G, Homann N, Wilhelm G, Schuch G, Stoehlmacher J, Derigs HG, Hegewisch-Becker S, Grossmann J, Pauligk C, Atmaca A, Bokemeyer C, Knuth A, Jäger E; Arbeitsgemeinschaft Internistische Onkologie. Phase III trial in metastatic gastroesophageal adenocarcinoma with fluorouracil, leucovorin plus either oxaliplatin or cisplatin: a study of the Arbeitsgemeinschaft Internistische Onkologie. J Clin Oncol. 2008; 26(9): 1435-42. doi: 10.1200/JCO.2007.13.9378.

[28] Higuchi K, Koizumi W, Yamada Y, Nishikawa K, Gotoh M, Fuse N, Sugimoto N, Nishina T, Amagai K, Chin K, Niwa Y, Negoro Y, Imamura H, Tsuda M, Yasui H, Fujii H, Yamaguchi K, Yasui H, Hamada C, Hyodo I. Randomized phase III study of S-1 plus oxaliplatin versus S-1 plus cisplatin for first-line treatment of advanced gastric cancer. Proc ASCO 2013; abstr 60

[29] Kang YK, Kang WK, Shin DB, Chen J, Xiong J, Wang J, Lichinitser M, Guan Z, Khasanov R, Zheng L, Philco-Salas M, Suarez T, Santamaria J, Forster G, McCloud PI. Capecitabine/cisplatin versus 5-fluorouracil/cisplatin as first-line therapy in patients with advanced gastric cancer: a randomised phase III noninferiority trial. Ann Oncol. 2009; 20(4): 666-73. doi: 10.1093/annonc/mdn717.

[30] Schubbert S, Shannon K, Bollag G. Hyperactive Ras in developmental disorders and cancer. Nat Rev Cancer. 2007; 7(4): 295-308.

[31] Ding L, Getz G, Wheeler DA, Mardis ER, McLellan MD, Cibulskis K, Sougnez C, Greulich H, Muzny DM, Morgan MB, Fulton L, Fulton RS, Zhang Q, Wendl MC, Lawrence MS, Larson DE, Chen K, Dooling DJ, Sabo A, Hawes AC, Shen H, Jhangiani SN, Lewis LR, Hall O, Zhu Y, Mathew T, Ren Y, Yao J, Scherer SE, Clerc K, Metcalf GA, Ng B, Milosavljevic A, Gonzalez-Garay ML, Osborne JR, Meyer R, Shi X, Tang Y, Koboldt DC, Lin L, Abbott R, Miner TL, Pohl C, Fewell G, Haipek C, Schmidt H, Dunford-Shore BH, Kraja A, Crosby SD, Sawyer CS, Vickery T, Sander S, Robinson J, Winckler W, Baldwin J, Chirieac LR, Dutt A, Fennell T, Hanna M, Johnson BE, Onofrio RC, Thomas RK, Tonon G, Weir BA, Zhao X, Ziaugra L, Zody MC, Giordano T, Orringer MB, Roth JA, Spitz MR, Wistuba II, Ozenberger B, Good PJ, Chang AC, Beer DG, Watson MA, Ladanyi M, Broderick S, Yoshizawa A, Travis WD, Pao W, Province MA, Weinstock GM, Varmus HE, Gabriel SB, Lander ES, Gibbs RA, Meyerson M, Wilson RK. Somatic mutations affect key pathways in lung adenocarcinoma. Nature. 2008; 455(7216): 1069-75. doi: 10.1038/nature07423. 
[32] Saal LH, Holm K, Maurer M, Memeo L, Su T, Wang X, Yu JS, Malmström PO, Mansukhani M, Enoksson J, Hibshoosh H, Borg A, Parsons R. PIK3CA mutations correlate with hormone receptors, node metastasis, and ERBB2, and are mutually exclusive with PTEN loss in human breast carcinoma. Cancer Res. 2005; 65(7): 2554-9.

[33] Lee SH, Lee JW, Soung YH, Kim HS, Park WS, Kim SY, Lee JH, Park JY, Cho YG, Kim CJ, Nam SW, Kim SH, Lee JY, Yoo NJ. BRAF and KRAS mutations in stomach cancer. Oncogene. 2003; 22(44): 6942-5.

[34] Shimoyama S. BRAF mutations and their implications in molecular targeting therapies for gastrointestinal cancers. J Pharmacogenom Pharmacoproteomics 2011; 2: e102. doi: 10.4172/2153-0645.1000e102

[35] Deng N, Goh LK, Wang H, Das K, Tao J, Tan IB, Zhang S, Lee M, Wu J, Lim KH, Lei Z, Goh G, Lim QY, Tan AL, Sin Poh DY, Riahi S, Bell S, Shi MM, Linnartz R, Zhu F, Yeoh KG, Toh HC, Yong WP, Cheong HC, Rha SY, Boussioutas A, Grabsch H, Rozen $\mathrm{S}$, Tan P. A comprehensive survey of genomic alterations in gastric cancer reveals systematic patterns of molecular exclusivity and co-occurrence among distinct therapeutic targets. Gut. 2012; 61(5): 673-84. doi: 10.1136/gutjnl-2011-301839.

[36] Kiyose S, Nagura K, Tao H, Igarashi H, Yamada H, Goto M, Maeda M, Kurabe N, Suzuki M, Tsuboi M, Kahyo T, Shinmura K, Hattori N, Sugimura H. Detection of kinase amplifications in gastric cancer archives using fluorescence in situ hybridization. Pathol Int. 2012; 62(7): 477-84. doi: 10.1111/j.1440-1827.2012.02832.x.

[37] Prahallad A, Sun C, Huang S, Di Nicolantonio F, Salazar R, Zecchin D, Beijersbergen RL, Bardelli A, Bernards R. Unresponsiveness of colon cancer to BRAF(V600E) inhibition through feedback activation of EGFR. Nature. 2012; 483(7387): 100-3. doi: 10.1038/nature10868.

[38] Shimoyama S. Unraveling trastuzumab and lapatinib in gastric cancer. Future steps. Mol Clin Oncol 2014; 2 (2): 175-181. DOI: 10.3892/mco.2013.218

[39] Lordick F, Kang YK, Chung HC, Salman P, Oh SC, Bodoky G, Kurteva G, Volovat C, Moiseyenko VM, Gorbunova V, Park JO, Sawaki A, Celik I, Götte H, Melezínková H, Moehler M; Arbeitsgemeinschaft Internistische Onkologie and EXPAND Investigators. Capecitabine and cisplatin with or without cetuximab for patients with previously untreated advanced gastric cancer (EXPAND): a randomised, open-label phase 3 trial. Lancet Oncol. 2013; 14(6): 490-9. doi: 10.1016/S1470-2045(13)70102-5.

[40] Waddell TS, Chau I, Barbachano Y, de Castro DG, Wotherspoon A, Saffery C, Middleton GW, Wadsley J, Ferry DR, Mansoor W, Crosby TDL, Coxon FY, Smith D, Waters JS, Iveson T, Falk S, Slater S, Okines AFC, Cunningham D. A randomized multicenter trial of epirubicin, oxaliplatin, and capecitabine (EOC) plus panitumumab in advanced esophagogastric cancer (REAL3). Proc ASCO 2012; abstr LBA4000

[41] Hecht JR, Bang Y-J, Qin S, Chung H-C, Xu J-M, Park JO, Jeziorski K, Shparyk Y, Hoff PM, Sobrero AF, Salman P, Li J, Protsenko S, Buyse ME, Afenjar K, Kaneko T, Kemn- 
er A, Santillana S, Press MF, Slamon DJ. Lapatinib in combination with capecitabine plus oxaliplatin (CapeOx) in HER2-positive advanced or metastatic gastric, esophageal, or gastroesophageal adenocarcinoma (AC): The TRIO-013/LOGiC Trial. Proc ASCO, 2013; abstr LBA4001

[42] Maughan TS, Adams RA, Smith CG, Meade AM, Seymour MT, Wilson RH, Idziaszczyk S, Harris R, Fisher D, Kenny SL, Kay E, Mitchell JK, Madi A, Jasani B, James MD, Bridgewater J, Kennedy MJ, Claes B, Lambrechts D, Kaplan R, Cheadle JP; MRC COIN Trial Investigators. Addition of cetuximab to oxaliplatin-based first-line combination chemotherapy for treatment of advanced colorectal cancer: results of the randomised phase 3 MRC COIN trial. Lancet. 2011; 377(9783): 2103-14. doi: 10.1016/ S0140-6736(11)60613-2.

[43] Asaoka Y, Ikenoue T, Koike K. New targeted therapies for gastric cancer. Expert Opin Investig Drugs. 2011; 20(5): 595-604. doi: 10.1517/13543784.2011.566863. 
